eines klaren Destillates, welches nur wenig Essigsäure und andere fremdartige Beimischungen enthält, erhalten, und kann ohne Rectification zu vielen Zwecken benutzt werden. Das Präparat reducirt eine ammoniakalische salpetersaure Silberlösung in der Kälte nach 2-3 Minuten. Zur Darstellung von Aldehyd-Ammoniak kann man jenes Präparat mit einem gleichen Volumen Aether vermengen und dann Ammoniak durch die Mischung leiten; ist das Aldehyd gesätligt, so scheidet sich Aldehyd-Ammoniak in glänzenden rhombischen Krystallen aus. Die Verfasser prüften die Empfindlichkeit des Aldehyds auf salpetersaures Silberoxyd und fanden, dass 1 Theil salpetersaures Silberoxyd in 1000 Theilen Wasser gelöst, mit etwas Aldehyd-Ammoniak erwärmt, einen Metallspiegel abschied; bei 2000 Theilen Wasser war derselbe nur an einzelnen Stellen bemerkbar unter dunkel-purpurgrüner Färbung der Fliissigkeit. Ein Theil auf 10000 Theile Wasser färbte sich nur und 2-3 Minuten lang gelinde erwärmt, ziemlich dunkel-rothgrün. Diese Färbung war noch deutlich bei 20000 Theilen Wasser, sogar noch bei 40000 Theilen Wasser. (Chemical Gazette 1846. - Pharm. Centrbl. 1846. No.47.) B.

\title{
Ueber die Amide.
}

Wird nach Malaguti ein Theil Oxamid mit 4 Theilen Salpetersäure von 1,35 spec. Gew. gekocht, so entwickelt sich 1 Vol. Stickstoff, 1 Vol. Stickstoffoxydul und 2 Volumen Kohlensäure, also dieselben Producte, die beim Kochen von 1 Aeq. salpetersaurem Ammoniak und 1 Aeq. Oxalsäure gebildet werden. Krystallisirtes oxalsaures Ammoniak im Verschlossenen einer Temperatur von $220^{\circ}$ ausgesetzt, giebt kohlensaures Ammoniak und Kohlenoxydgas. Oxamid in einer hermetisch verschlossenen Metallröhre verwandelt sich bei $310^{\circ}$ schnell in Cyan, Kohlenoxydgas und kohlensaures Ammoniak $\left(\mathrm{C}^{2} \mathrm{H}^{2} \mathrm{NO}^{2}=\mathrm{Cy}+2 \mathrm{HO}\right)$; dasselbe mit Sand gemengt in einer Röhre bei $300-330^{\circ}$ erhitzt, giebt dieselben Producte.

Chloracetamid liefert bei schwacher Rothgliuhhitze viel Kohlensäure, gasförmiges Chlorcyan, Kohlenoxydgas und etwas Phosgengas $\left(\mathrm{C}^{4} \mathrm{Cl}^{3} \mathrm{O}^{2} \mathrm{H}^{2} \mathrm{~N}=\mathrm{C}^{2} \mathrm{CyCl}+\mathrm{Cl}^{2} \mathrm{H}^{2}\right.$ $+\mathrm{C}^{2} \mathrm{O}^{2}$ ); mit Wasser in einer verschlossenen Glasröhre über $100^{\circ}$ erwärmt, entsteht Chloroform und kohlensaures Ammoniak, ohne vorherige Bildung von chloressigsaurem Ammoniak. Bei $130^{\circ}$ findet man das Chloracetamid noch unverändert, während chloressigsaures Ammoniak schon 
bei $112-115^{\circ}$ Chloroform und kohlensaures Ammoniak liefert.

Flüssiges Ammoniak mit Schleimsäure-Aether in Berührung giebt Mucamid; eine weisse, in kochendem Wasser leicht lösliche, heim Erkalten in mikroskopischen Nadeln niederfallende Substanz. Das Mucamid $=\mathrm{C}^{6} \mathrm{H}^{6} \mathrm{O}^{6} \mathrm{~N}$ ist geschmacklos, unlöslich in Alkohol und Aether, sein spec. Gew. ist $=1,589$ bei $13,5^{\circ}$. Mit Wasser entsteht bei 136 - $140^{\circ}$ schleimsaures Ammoniak; die kochende Lösung mit ammoniakalischem essigsaurem Bleioxyd vermischt, setzt ammoniakalisches chromsaures Bleioxyd $=\mathrm{C}^{\prime \prime}$ $\mathrm{H}^{8} \mathrm{O}^{14}, 2 \mathrm{PbO}, \mathrm{H}^{3} \mathrm{~N}+6 \mathrm{HO}$ ab, welches durch Schwefelwasserstoff in Schwefelblei und saures schleimsaures Ammoniak verwandelt wird. Das schleimsaure Ammoniak auf $220^{\circ}$ erhitzt, erweicht und färbt sich unter Entwicklung von $\mathrm{CO}^{2}$, Wasser, kohlensaurem Ammoniak, Brenzschleimsäure und einem eigenthümlichen Amid; im Rückstande findet sich Kohlenstoff und Paracyan. Dieselben Producte liefert das Mucamid, welches bei $200^{\circ}$ sich bräunt, bei $208^{\circ}$ viel Wasser, bei $220^{\circ}$ die andern Stoffe entwickelt, bei $240^{\circ}$ ist die Zerselzung beendet, $\left(C^{12} \mathrm{H}^{12}\right.$ $\mathrm{N}^{2} \mathrm{O}^{12}=\mathrm{C}^{4} \mathrm{~N}^{2}+\mathrm{C}^{8}+12 \mathrm{HO}$ ); hier treten Wasser, Kohle und Paracyan in beträchtlicher Menge auf, wogegen bei Zersetzung des schleimsauren Ammoniaks in der Hitze Brenzschleimsäure, das Amid, kohlensaures Ammoniak, Kohlensäure und Wasser in vorwaltender Menge gebildet werden. Das Amid /Pyromucamide biamidée $=\mathrm{C}^{10} \mathrm{H}^{2}$ $\mathrm{O}^{2}, 2 \mathrm{H}^{3} \mathrm{~N}$, welches man bei der trocknen Destillation des Mucamids oder schleimsauren Ammoniaks erhält, kann leicht durch Umkrystallisiren von anhängender Brenzschleimsäure befreit werden. Es schmeckt zuckerartig, ist in Weingeist und Aethor löslich, in kaltem Wasser nur wenig, schmilat bei $175^{\circ}$, wobei es sich färbt und anfängt sich zu zersetzen; bei $260^{\circ}$ kocht es. Beim Kochen mit Alkalien entwickelt sich Ammoniak. Das Pyromucamid $=\mathrm{C}^{10} \mathrm{H}^{6} \mathrm{NO}^{4}$ schmeckt kaum zuckerartig, löst sich in Alkohol, Aether und Wasser, schmilzt bei $330-132^{\circ}$, wobei es grün, dann blau, später violett und endlich schwarz wird.

Die Weinschleimsäure (Acide mucovinique) scheidet sich öfter bei Darstellung des Schleimsäure-Aethers, wenn derselbe in noch nicht ganz reinem Zustande in wässerige Lösung kommt, ab, unter Entwicklung von Alkoholgeruch. Man erhält beim Verdunsten einen sauren Rückstand; durch wiederholtes Behandeln mit Weingeist, Auflösen in Wasser und zwei- bis dreimaliges Umkrystalli- 
siren exhält man einen weissen Körper von asbestartigem Ansehen in kleinen Prismen, deren Basis ein Parallelogramm ish, welcher sich leicht löslich in Wasser, wenig löslich in Alkohol zeigt; schmeckl sauer, schmilzt bei $190^{\circ}$ unter Veränderung, und nimmt ein glasartiges Ansehen an. Bei längerm Liegen entsteht aber wieder eine undurchsichtige weiche Masse. 1 Aeq. jenes Körpers (der Weinschleimsäure) absorbirte unter Erwärmung 1 Aeq. Ammoniak. Es bildete sich ein $\mathrm{Salz}=\mathrm{C}^{16} \mathrm{H}^{14} \mathrm{O}^{16}, \mathrm{NH}^{3}$, welches leicht löslich und geschmacklos ist und saver reagirt; die Lösung fältt die Salze von Silber, Blei, Kupfer, Baryt, Strontian, einige vou Kalk, nicht die des Zinks, der Magnesia etc. Die Niederschläge sind in Essigsäure löslich. Weinschleimsäurelösung mit Silberoxyd gekocht, reducirt einen Theil Silberoxyd unter Bildang einer leicht explodirenden Silberverbindung. Auch das Mucamid redacirt Silber beim Kochen aus ammoniakalischem salpetersaurem Silberoxyd. (Compt. rend. XXII. - Pharm. Centrbl. 1846. No. 58.) $B$

\section{Fermentoleum Conii}

fand Landerer von durchaus nicht narkotischem Geruche, scharfem brennendem Geschmacke, weisser, wenig ins Gelbliche neigender Farbe, leicht löslich in Alkohol, Aether, ätherischen und fetten Oelen. Auf Thiere äusserte es zu einigen Tropfen keine nachtheilige Wirkung. (Buchn. Repert. 41. 2.)

Diese Beobachtungen stimmen mit den von mir bei Fermentoleum Chelidonii gemachten sehr überein. Bley.

\section{Einwirkung der Salpetersäure auf Brucin.}

L a urent bezeichnet mit dem Namen Cacotheline diejenige Substanz, welche durch fortgesetzte Einwirkung der Salpetersäure auf Brucin hervorgerufen wird. Sie ist orange-röthlich gefärbt, krystallisirbar, und besteht aus $\mathrm{C}^{21} \mathrm{H}^{22} \mathrm{~N}^{4} \mathrm{O}^{10}$. Ein Aequivalent Brucin und $3 \mathrm{Aeg}$. Salpetersäure ergeben 1 Aeq. Salpeter-Aether und Aeq. Aq., der Rest der Elemente bedingt das Entstehen der neuen Substanz. Ammoniak zerlegt diese in verschiedene Producte; unter ihnen ist eine alkalische Basis besonderer Art befindlich, welche die Elemente der salpetrigsauren Dämpfe mit sich führt, und bei erhöheter Temperalar wieder zerlegt wird. (Journ. de Pharm. et de Chimie. Août 1846. p. 153.) Witting. 